\title{
Gender Equality for Sustainable Development: Focus on Interpreting Gender Relation in YAOI Doujinshi Love Heat at Tropical Island
}

\author{
P A Dewi \\ Faculty of Humanities, Universitas Bina Nusantara, Jakarta, Indonesia \\ putri.dewi@binus.edu
}

\begin{abstract}
The present study examines the negotiation of gender identity in the Japanese YAOI genre by focusing on the YAOI doujinshi (fan-made manga consisting of love stories between two male characters) titled, Love Heat at Tropical Island. More specifically, based on Kitzinger's concept of heterosexuality and Yomota's basic manga character codes, this study performs a textual analysis of the comic panels in order to determine how the authors (in this case, the Indonesian fujoshi) depict their vision of gender relation negotiation. The findings show that the negotiation of gender relation in the work is transnational, i.e., the acculturation of Japanese, Indonesian, and Western gender identity.
\end{abstract}

Keywords: Gender Relation, YAOI Doujinshi, Manga

\section{INTRODUCTION}

Gender equality is one of main goal in creating sustainable development in one's country. Based on United Nation data many developing countries still struggle to achieve gender equality in their daily life, one of them is Indonesia. One of the problem achieving gender equality in Indonesia is gender-based stereotype in gender relation. Patriarchal ideology still prevalence in the interaction between men and women in Indonesia. Gender roles stereotype between men and women still controlled the majority of socio-cultural life. But, with the advance and the development of communication and technology such as the internet emerge virtual space to give and take opinions and ideology from people around the globe. There is no boundaries and time is irrelevant. Including ideology concerning gender stereotype and roles in the daily interaction.

The concept of sustainable development represents a shift in understanding of humanity's place on the planet, but it is open to interpretation of being anything from almost meaningless to of extreme importance to humanity. Whatever view is taken, it is clearly an area of contention [1]. Therefore, in this paper I would like to argue that to achieve gender equality the society must have a clear understanding about gender and that understanding applied in our daily interaction. In this paper, I would like to argued that popular culture such as comic have become one of media for gender negotiation, especially gender relation.

Increased Access to new technologies such as digital photography, video, computerapplications, and the Internet has rapidly expanded the territory of children's and youth self-directedartistic exploration beyond the conventional medium of pencil and paper. Contemporarychildren and youth areeager to pick up a digital camera to snap a picture or 
record a video, or manipulate a mouse to doodle in a computer drawing program [2]. Jenkins [3] stated that this kind of participatory culture is anew creative space that prevalence in youth daily life. Within this creative space, youth have access to express and communicate issues that tabooed in society, such as sexuality, alternative gender, homosexuality and pornography.

Within this demographic, the fujoshi have created their own narratives called, YAOI doujinshi or fan-made manga consisting of love stories between two male characters. Gailbraith [4] explained that fujoshi (腐女子)means "rotten girl," which is a homonym of fujoshi, meaning "woman" or "lady." However, this term also refers to girls who read the YAOI genre (also known as "Boys' Love" or BL). In general, these female manga fans have a higher degree of interest than regular manga readers.

Welker [5] stated that the fujoshi generally incorporate two main male characters in their YAOI doujinshi (based on their favorite male manga characters) and add new dialogs, settings, and backgrounds. For example, they use the main male characters from a sports genre in which they compete against one another and transform the narrative into a love story between the two characters. Thus, Yaoi doujinshi generally refer to homoerotic stories aimed toward heterosexual female manga readers [4]-[6].

Previous studies have focused on the practices of Japanese women who identified themselves as fujoshi [5], [7], [8]. Meanwhile, in Indonesia, research mainly concentrated on the fujoshi, as agents for establishing an Indonesian fujoshi community. However, limited studies have focused on the YAOI doujinshi created by Indonesian fujoshi, especially in regard to their portrayal of gender identity.

Therefore, the present study examines the gender identity negotiation in the Japanese YAOI genre by focusing on the YAOI doujinshi titled, Love Heat at Tropical Island (hereafter referred to as LHATI). More specifically, based on Jenkin's concept of textual poacher and Yomota's basic manga character codes; it performs a textual analysis of the comic panels in order to determine how the authors depict their vision of gender identity.

\section{LITERATURE REVIEW}

Theoretical framework in this paper apply several concepts, such as Connell's masculinity [9] and Kitzinger's heterosexuality [10] to analyze the appropriation of Aomine and Kuroko relationship from friendship to marriage couple. Comic and manga elements were applied to analyze the comic panels in LHATI. Jenkin's textual poachers [3] added to explain the appropriation process from original story $(\mathrm{KnB})$ to YAOI doujinshi (LHATI). Thus, the theoretical framework scheme describes below:

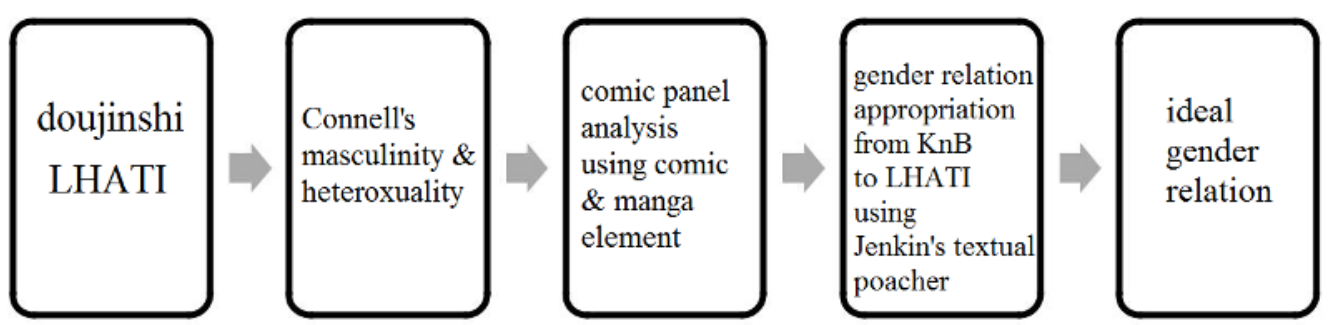

Figure 1. Theoretical Framework.

Based on the scheme above, doujinshi is positioned as a text that apply comic and manga elements. In the sense, doujinshi can be analyzed as a comic but mostly using manga elements. 
On one side, characters visualization, sound effects, emotion expression mostly applying manga elements. Meanwhile, panel layouts, panel transitions, verbal texts and visual texts relation mostly applying comic elements to analyze them. [11] explained that the sequential images on comic were not only images but a way of looking something. Eisner [12] also stated that comic is expression and communication media for the artist. Therefore, it can be said that comic is not imply sequential images but as media for interpreting meaning and expression looking our daily reality.

As mentioned by Gailbraith [4] and Welker [5], the purpose of the YAOI doujinshi is to appropriate two main characters from the original story and transform them into two male lovers; that is, the seme (the dominant male) and the uke (the submissive male). Hence, in LHATI, Aomine is the seme and Kuroko is the uke. Moreover, the seme-uke relationship is visualized according to their physical appearances, i.e., the seme includes masculine characteristics, whereas the $u k e$ includes more feminine features.

Jenkin's [3] argued textual poachers describes a social group struggling to define its ownculture and to construct its own community within the context ofwhat many observers have described as a postmodern era; itdocuments a group insistent on making meaning from materialsothers have characterized as trivial and worthless. In other word, textual poaching positioned LHATI as expression media for fujoshi to negotiate gender identity in homoerotic narrative. Thus, the negotiation of gender identity of Aomine and Kuroko will be analyzed by using Jenkins's textual poacher concept and Yomota's basic manga character codes [8].

\section{RESULT AND DISCUSSION}

This sub-section explained the appropriation of the nature of Aomine and Kuroko gender relation from original story $(\mathrm{KnB})$ to LHATI. Originally Aomine and Kuroko are two main characters in shounen manga title Kuroko no Basuke $(\mathrm{KnB})$. In $\mathrm{KnB}$ their relationship is friendship also basketball rival. But, in LHATI their relationship appropriated by minatu94 to marriage couple. From the appropriation process we can have an understanding how Indonesia fujoshi (mainly young adult female) negotiate and interpreted gender relation through popular media such as comic.

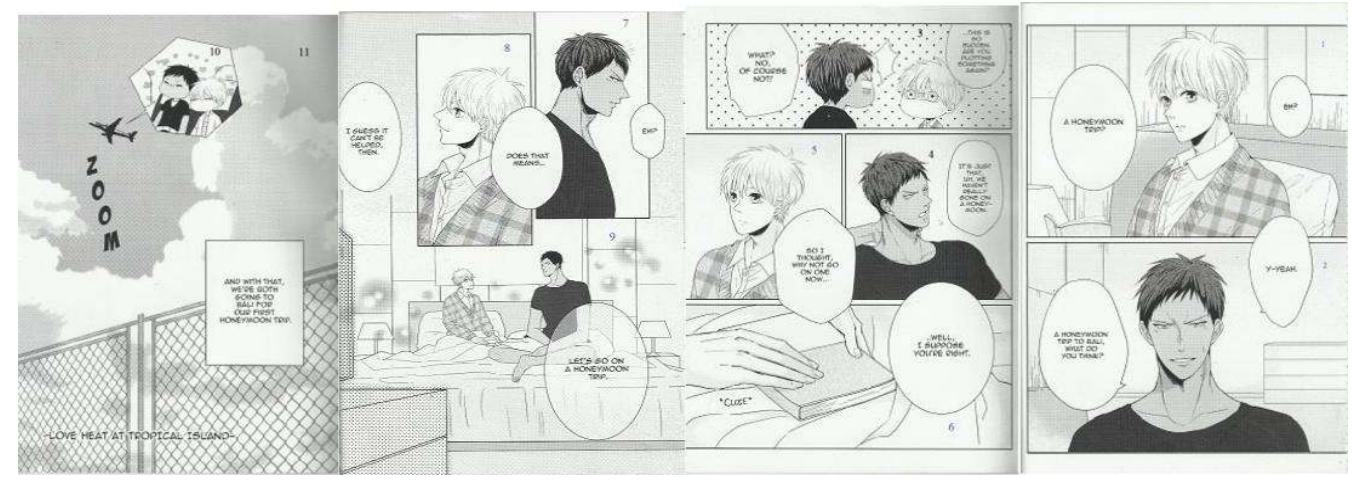

Figure 2. Aomine and Kuroko interaction in LHATI (read from right to left)[13]

Based on the panels above, most of the them are using medium closeup and extreme long shot or panoramic [14] Medium closeup shot frequently used to focus the changing and the difference of Aomine and Kuroko emotion code. Meanwhile, panoramic shot was used to 
highlight different background or setting to accentuate the emotion and action code of Aomine and Kuroko. Attention units in this scene mostly mono for the purpose of focusing the reader's attention to Aomine and Kuroko interaction in the panels [11] stated that Japanese comic have a different panels layout from Western comic. In the sense, their layout was not organized with a fixed sequence, their layout is a mix of perspectives and panel shots [14].

The usage of bird eye view, worm eye view, and straight-ahead perspective [14] are useful so that the panel is arranged dynamically and attractively. In addition, these various points of view can also be used to interpret the cultural and social codes in LHATI. The three perspectives mentioned above can be used to analyze the interaction between Aomine and Kuroko. The strategically placement of the various points of view of the objects in the panel is useful to show the interpretation of cultural and social meanings contained in LHATI [14]

Aomine and Kuroko's conversation scene in the bedroom of their apartment in LA, America. This scene consists of 11 panels. Most panel movements in this scene usetransition between subjects (panels 1-2, 4-5, and 7-8) but they are still in one idea or event [11]. Event 1 describes Aomine and Kuroko's conversation in the apartment's bedroom in LA. The bedroom is a personal domain. Usually there is no other person besides the bedroom owner. This shows that someone can be himself or herself in this space. Thus, it can be concluded in this scene how the author wants to express the things that the two characters feel openly. There are several other elements that can be marked in the analysis of this one event, as well as the dress style of Aomine and Kuroko. Kuroko's clothing style is very concealed and conservative. This is shown on panels 1, 5, and 9. Kuroko wore plain white pajama, plaid sweater, the legs were covered with blanket. While Aomine's style of clothing is open and relaxed. This is shown on panels 2,3,4,7 and 9. Aomine wore black T-shirt and white short.

The 'male' and 'female' gender visual codes were initially seen through visualizing the different Persona codes between Aomine and Kuroko.Aomine's persona code is described in the 'male' visual code while Kuroko is in the 'female' visual code. Persona code of the two characters that distinguishes them is the shape of the'female' character's face, nose, and mouth is smaller than the 'male'. Smaller mouth and nose shape gives a cute and funny effect while big mouth and nose show male virility. According to Sihombing [8] Emotion code and Action code show how visual differences actually do not relate to the physical appearance of the character's gender identity. The two codes show the inequality of power and dominance relation. For example, seme characters are visualized using expressions or poses showing power or dominance while the uke character shows timidity or fragility.

The misalignment of power and dominance relation can also be represented through objects, such as clothing and verbal texts that provide information about their social level and position.Therefore, the relation between Aomine and Kuroko is based on emotion and the action code that can be observed as follows. First, Aomine's Emotion code in panels 2 and 4 uses the mono attention unit and taking a medium close up image shows a hesitant and uncomfortable attitude when asking Kuroko to go honeymoon. Aomine's attitude is shown through the expression on his face, which is the outer edge of the eyebrow that swooped upward, wrinkled in the middle of the forehead, eyes were approaching toward the top of the nose. While the lower part of the eye was marked by an almost vertical line that showed a red hue, and the mouth was open like a grimace. In addition, Aomine's emotions on panel 4 were supported by the Emotion code in the form of her palm that was looped to the back of Kuroko's neck. Aomine's eyes didn't look straight to Kuroko.

Aside from the Emotion code and Aomine Action code, the form of the word balloon also shows Aomine and Kuroko's emotional expressions. On one occasion, the Aomine word balloon was oval in imperfect form. The shape was slightly bumpy. This shows how Aomine's 
voice was a little unstable or hesitant when he asked Kuroko to go honeymoon in Bali, it seemed like he's hiding something. Especially on panel 3, Aomine's balloon said more waves when Kuroko asked if he was hiding something. While the word Kuroko balloon in every moment in the panel is always in perfect oval shape, which indicates the round and firmness of his heart. In addition, there is a depiction of chibi or super deformed (SD) characters on panel 3 on illustrations of Aomine and Kuroko. According to Okum [14] the appearance of chibi or elementary illustrations is usually for interlude with comedy or expressing extreme emotions. In this case, the extreme emotion shown was Aomine's extreme emotions when asked by Kuroko.Based on the emotion code, action code, and word balloon chosen by the author, Aomine shows Aomine's lack of confidence when trying to get Kuroko to do romantic or sentimental things as seen in panels 2.3 , and 4 . This contrasts with emotion code, action code, and Kuroko's word balloon which shows calm and not emotional. Even though Kuroko was suspicious that something was hidden by Aomine, it was seen from Kuroko's balloon in panel 3 how he still showed himself talking using a normal voice.

Based on emotion code, action code, word balloons, and chibi / elementary illustrations Aomine and Kuroko show how Kuroko's nature is more dominant than Aomine in the room, as a personal space. Kuroko who is positioned as uke shows more maturity and not emotional. Meanwhile, Aomine shows the 'male' social code that is uncomfortable dealing with talking about feelings or the need to be romantic to his partner.Based on the form and arrangement of LHATI's doujinshi panel, there is a contradiction in the power and dominant relation in the relationship between the two main characters. Moments in the one event panel show how Kuroko is more emotionally dominant than Aomine. However, through panel placement and panel composition, Aomine's position remains more dominant. This contradiction is more clearly indicated by the panel placement and shooting angle on panels 7 and 8. On panel 7, Aomine is depicted using bird eye view and Kuroko in panel 8 uses a worm's eye view. In composition, Aomine's position looks superior or higher than Kuroko's. In this scene, Kuroko's action code was also observed which he slightly looked up at Aomine and his hand was placed on top of the book. This action code shows the feminine pose commonly found in shoujo manga characters. Furthermore, on panel 9, without using a panel frame and filling almost the entire page, the author can be observed creating a peaceful and reasonable atmosphere [12] using extreme long shot shooting angles. This corner shows the whole room where Aomine and Kuroko are in dialogue.

At the beginning of its emergence, the BL and YAOI texts were considered as passive resistance of Japanese women to gender relation in Japanese society which were patriarchal and male-dominated [5], [7], [15]. Apparently from the observations made on LHATI's text, there are findings that show the concept above is not that simple. Although at the initial stage of YAOI's text observation as if deconstructing the images and representations of men in a homosexual love relationship, at the next stage of observation it turns out that the sociocultural code of heterosexual romantic stories still exists. For example, how true happiness for the uke as a 'female' side can be achieved by finding the ideal and romantic partner who accepts and loves him for who he is. This shows that the code in the heterosexual romance plot is still considered ideal in a love relationship. This kind of heteronormative element appears in the interaction between Aomine and Kuroko in LHATI.

Based on the explanation of this example, it can be concluded that gender negotiation is focused on masculine-feminine gender relation which represented using seme-uke relation of male in marriage institution. Masculine and feminine gender relation based on feminist approach is viewed as a form of male domination on female. The second wave feminist discussing woman subordination by man sites by is the marriage institution. Furthermore, [9] 
mentioned, masculine and feminine gender relation is regulated based on the idea of male domination on female, one of them is in themarriage institution. But, in LHATI the institution of marriage is seen differently.

In the senses that on LHATI's text analysis and doujinshi panel, it can be seen that the marriage institution is not a symbol of man oppression against woman. In other words, the marriage institution is not a scourge for a woman like a marriage in a Western context.

\section{CONCLUSION}

Gender relation that implies a male domination / subordination relationship to woman in LHATI can be negotiated through a compromise between the two parties. The main focus of gender relation in LHATI is to show that marriage is not used as an arena to advance each other's egos. Rather, as a place to find a midpoint that can satisfy the needs of both parties.

So, based on the explanation of the series of events in the LHATI panel, it can be concluded that the gender negotiation takes place in the form that has been appropriated by Fujoshi Indonesia, through the LHATI doujinshi. This new form shows how these forms of negotiation are deliberately conducted by Fujoshi. They are presenting texts that are no longer purely the same as YAOI and BL in Japan, but have been appropriated through values in Indonesia, such as marriage.

\section{REFERENCES}

[1] B. Hopwood, M. Mellor, and G. O’Brien, "Sustainable development: mapping different approaches," Sustain. Dev., vol. 13, no. 1, pp. 38-52, 2005.

[2] O. Ivashkevich and S. Shoppell, "Appropriation, parody, gender play, and selfrepresentation in preadolescents' digital video production," Int. J. Educ. Arts, vol. 14, no. 2, 2012.

[3] H. Jenkins, Textual Poachers. Routledge, 2012.

[4] P. W. Galbraith, The Otaku Encyclopedia: An Insider's Guide to the Subculture of Cool Japan, 1st ed. Tokyo: kodansha, 2009.

[5] J. Welker, “A Brief History of Sounen'ai, Yaoi, and Boys Love,” in Boys Love Manga and Beyond, University Press of Mississippi, 2015, pp. 42-75.

[6] M. J. McLelland, "The Love Between 'Beautiful Boys'in Japanese Women's Comics," J. Gend. Stud., vol. 9, no. 1, pp. 13-25, Mar. 2000.

[7] M. Torn, "Fanning the Flames: Fans and Consumer Culture in Contemporary Japan," in Girls and Women Getting Out of Hand: The Pleasure and Politics of Japan's Amateur Comics Communit y, W. W. Kelly, Ed. Albany: New York: State University of New York Press, 2004, pp. 169-187.

[8] F. Sihombing, "On The Iconic Difference between Couple Characters in Boys Love Manga," Imange Narrat., vol. 12, no. 1, pp. 150-165, 2011.

[9] R. W. Connell, "Gender and Power Society, the Person, and Sexual Politics," SAGE, vol. 8 , no. 4, 1987.

[10] C. Kitzinger, "Heteronormativity in Action: Reproducing the Heterosexual Nuclear Family in After-hours Medical Calls," Soc. Probl., vol. 52, no. 4, pp. 477-498, 2005.

[11] McCloud, Understanding Comic. New York: harper, 1994.

[12] W. Eisner, Comic \& Sequential Art. Florida: poorhouse press, 1985.

[13] Minatu, Love Heat at Tropical Island The Basketball which Kuroko Plays. 2013.

[14] Okum, manga madness. Blue Ash, Ohio: F\&W Publications Inc., 2014. 
[15] K. Suzuki, Pornography or therapy? Japanese girls creating the yaoi phenomenon Millenium Girls: Today's Girls Around The World ed S A Inness. Lanham, Maryland: Rowman \& Littlefield Publishers, Inc, 1988. 